\title{
A systematic review of 30-day readmission after cranial neurosurgery
}

\author{
Michael D. Cusimano, MD, PhD, ${ }^{1,2}$ Iryna Pshonyak, BSc, ${ }^{1}$ Michael Y. Lee, ${ }^{1}$ and Gabriela Ilie, PhD² \\ 'Division of Neurosurgery, Keenan Research Centre and Li Ka Shing Knowledge Institute, St. Michael's Hospital, University of \\ Toronto; '2Dalla Lana School of Public Health and Department of Surgery, University of Toronto, Ontario; and ${ }^{3}$ Department of \\ Community Health and Epidemiology, Department of Urology, Faculty of Medicine, Dalhousie University, Halifax, Canada
}

OBJECTIVE The 30-day readmission rate has emerged as an important marker of the quality of in-hospital care in several fields of medicine. This review aims to summarize available research reporting readmission rates after cranial procedures and to establish an association with demographic, clinical, and system-related factors and clinical outcomes.

METHODS The authors conducted a systematic review of several databases; a manual search of the Journal of Neurosurgery, Neurosurgery, Acta Neurochirurgica, Canadian Journal of Neurological Sciences; and the cited references of the selected articles. Quality review was performed using the STROBE (Strengthening the Reporting of Observational Studies in Epidemiology) criteria. Findings are reported according to the PRISMA (Preferred Reporting Items for Systematic Reviews and Meta-Analyses) guidelines.

RESULTS A total of 1344 articles published between 1947 and 2015 were identified; 25 were considered potentially eligible, of which 12 met inclusion criteria. The 30-day readmission rates varied from $6.9 \%$ to $23.89 \%$. Complications arising during or after neurosurgical procedures were a prime reason for readmission. Race, comorbidities, and longer hospital stay put patients at risk for readmission.

CONCLUSIONS Although readmission may be an important indicator for good care for the subset of acutely declining patients, neurosurgery should aim to reduce 30-day readmission rates with improved quality of care through systemic changes in the care of neurosurgical patients that promote preventive measures.

https://thejns.org/doi/abs/10.3171/2016.7.JNS152226

KEY WORDS readmission; cranial neurosurgery; causes; outcomes; systematic review

I $\mathrm{N}$ recent years, readmission has become a predominant issue due to its burdens on the health care system, hospitals, insurers, and patients. It has been estimated that the yearly cost to Medicare of unplanned readmissions is $\$ 17.4$ billion..$^{24}$ In the US, reimbursement penalties have been instituted for early readmissions to improve quality of care under the Patient Protection and Affordable Care Act. ${ }^{2}$ Considering the health and financial costs associated with readmission, it is not surprising that reducing readmission rates has been deemed a public health priority. ${ }^{23,27}$ In neurosurgery, the connection between the rates of readmission and performance level is unclear and considerable debate exists regarding this association..$^{43} \mathrm{~A}$ recent study from Health Canada concluded that readmission rates are important for measuring the quality and efficiency of acute care. ${ }^{23}$ However, some researchers argue that a drop in readmission among neurosurgery patients may not be a positive indicator of health care and that unlike other divisions of care, early readmission and intervention in neurosurgery can ultimately prevent complications, serious morbidities, and disease progression. ${ }^{21}$ Hence, high rates of 30-day readmission in neurosurgery are suggested to be a sign of prudent care that may indicate better outcomes and higher quality of care. ${ }^{43}$

Recent studies report that primary diagnoses at readmission are related to surgery and that these complications are mostly preventable, according to the Agency for Healthcare Research and Quality. ${ }^{16,34}$ As a result, attempts have been made to identify causes and factors related to readmission rates and to introduce preventive measures to

ABBREVIATIONS CPT = current procedural terminology; DVT = deep venous thrombosis; LOS = length of stay; PE = pulmonary embolism; PRISMA = Preferred Reporting Items for Systematic Reviews and Meta-Analyses; STROBE = Strengthening the Reporting of Observational Studies in Epidemiology; VTE = venous thromboembolism. SUBMITTED September 22, 2015. ACCEPTED July 28, 2016.

INCLUDE WHEN CITING Published online October 21, 2016; DOI: 10.3171/2016.7.JNS152226. 


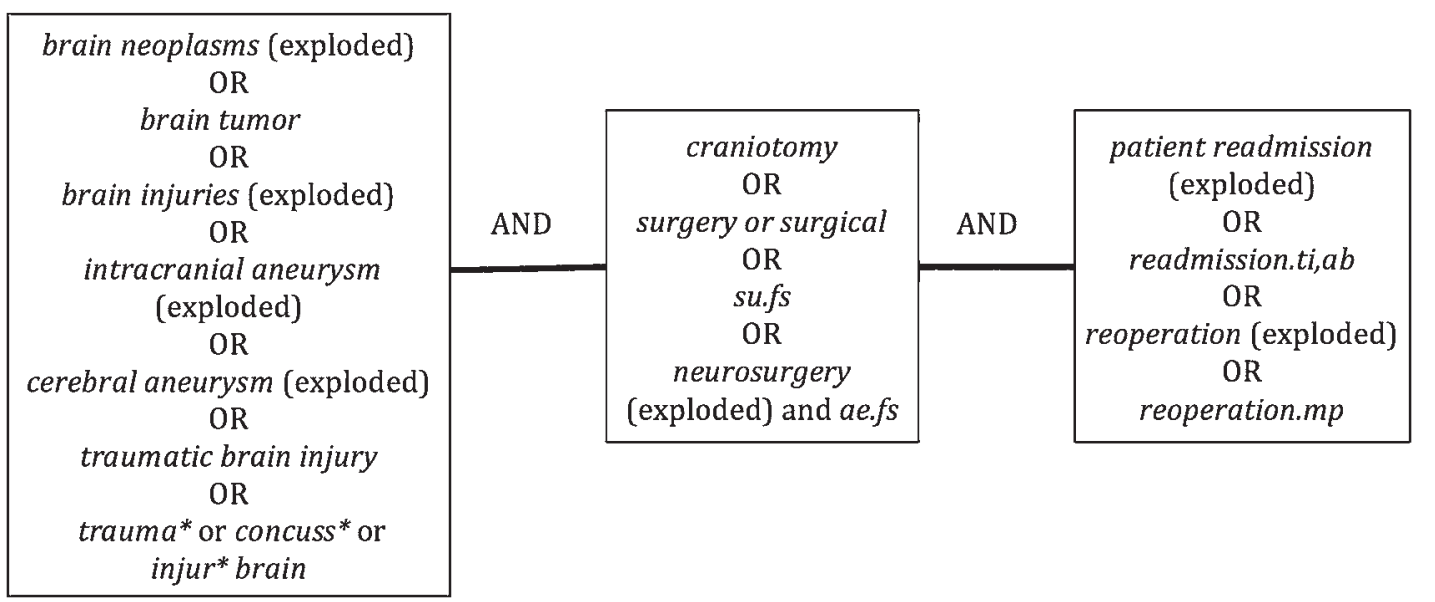

FIG. 1. Chart showing research strategy and terms used when searching through MEDLINE and EMBASE Classic.

reduce their impact, thereby improving patient care and reducing the cost to health care providers. In a number of other specialties, multifaceted interventions are now provided by health care professionals and have been shown to be effective in reducing readmission rates. ${ }^{23,29,39}$ However, these factors have yet to be summarized systematically for neurosurgical procedures and diagnoses. Such reports are crucial to understanding the causes of pathological entities that require cranial neurosurgery and subsequently developing strategies to prevent their occurrence.

In this review, our aims were 3 -fold. First, we aimed to summarize available research on 30-day readmission rates after cranial procedures in neurosurgery. Our second goal was to identify demographically at-risk populations, and the clinical and system-related factors associated with readmission in neurosurgery. Last, potential strategies to reduce the identified readmission risk factors in neurosurgery were discussed.

\section{Methods}

A total of 1344 articles were obtained from a systematic search of English-language literature using MEDLINE (1946-June 2014) and EMBASE Classic (1947-June 2014); a manual search of the Journal of Neurosurgery, Neurosurgery, Acta Neurochirurgica, Canadian Journal of Neurological Sciences; the cited references of the selected articles; and the "search cited" feature of PubMed. The search was limited to randomized controlled trials and observational, retrospective, and follow-up studies involving only human cohorts. Search terms are summarized in Fig. 1.

Studies that assessed readmission rates after the following procedures were included: craniotomy (for glioma and meningioma); transsphenoidal surgery (endoscopic pituitary, microscopic pituitary, transsphenoidal nonpituitary tumor); craniotomy for subdural hematoma; bur hole(s) for subdural hematoma; cerebral aneurysm repair by craniotomy and endovascular technique; ventriculoperitoneal shunt insertion and revision; endoscopic third ventriculostomy; surgical treatment of epilepsy by temporal lobectomy, amygdalohippocampectomy, hemispherectomy, callosotomy, and other procedures for seizures; or other neurosurgical cranial procedures for brain tumors, traumatic brain injury, subdural hematomas, cerebral aneurysms, hydrocephalus, and epilepsy.

Articles of interest must have reported the number of patients returning to the hospital after a cranial procedure and their demographic data and/or reasons for readmission. The studies were required to perform comparative analyses between a readmitted and a nonreadmitted group or between a readmitted and the overall group. Excluded studies comprised those that reported readmission as reoperation, complications, mortality, morbidity, or as part of a composite outcome.

Based on the inclusion and exclusion criteria, 25 articles were retained for full-text examination, of which 12 were chosen to be included in this review. Figure 2 is a PRISMA (Preferred Reporting Items for Systematic Reviews and Meta-Analyses) flow diagram, which illustrates the number of articles at each data acquisition level, the number of excluded articles, and the reasons for exclusion. Characteristics of study quality such as use of statistical analyses, generalizability, and external and internal validity were assessed by 2 of the authors (I.P. and M.L.) using STROBE (Strengthening the Reporting of Observational Studies in Epidemiology) criteria. ${ }^{48}$ The Cohen's kappa (к) of 0.78 for the agreement between the 2 raters was high. The PRISMA guidelines were used to report the results. ${ }^{30}$

\section{Results}

The 30-day readmission rates ranged from $6.0 \%$ to $23.89 \%$. All of the selected studies assessed readmission rates and identified causes for readmission or for vulnerable populations. ${ }^{6,9,16,32,34,36,38,42,43,47,50,52}$ Table 1 provides details of characteristics of each study. All except one Australian study were conducted in the US. ${ }^{50}$ All 12 studies were retrospective cohorts. Studies reported on data derived from time periods ranging from 1991 to 2013, and the sample size in each study varied from 100 to $18,506$.

Seven studies ${ }^{9,32,34,36,38,42,52}$ used ICD-9 or current procedural terminology (CPT) codes to identify the appropriate neurosurgical diagnoses and/or procedures. Nine of the 12 selected studies ${ }^{12,16,32,34,38,38,42,43,52}$ reported the significance of factors associated with 30-day readmission, 


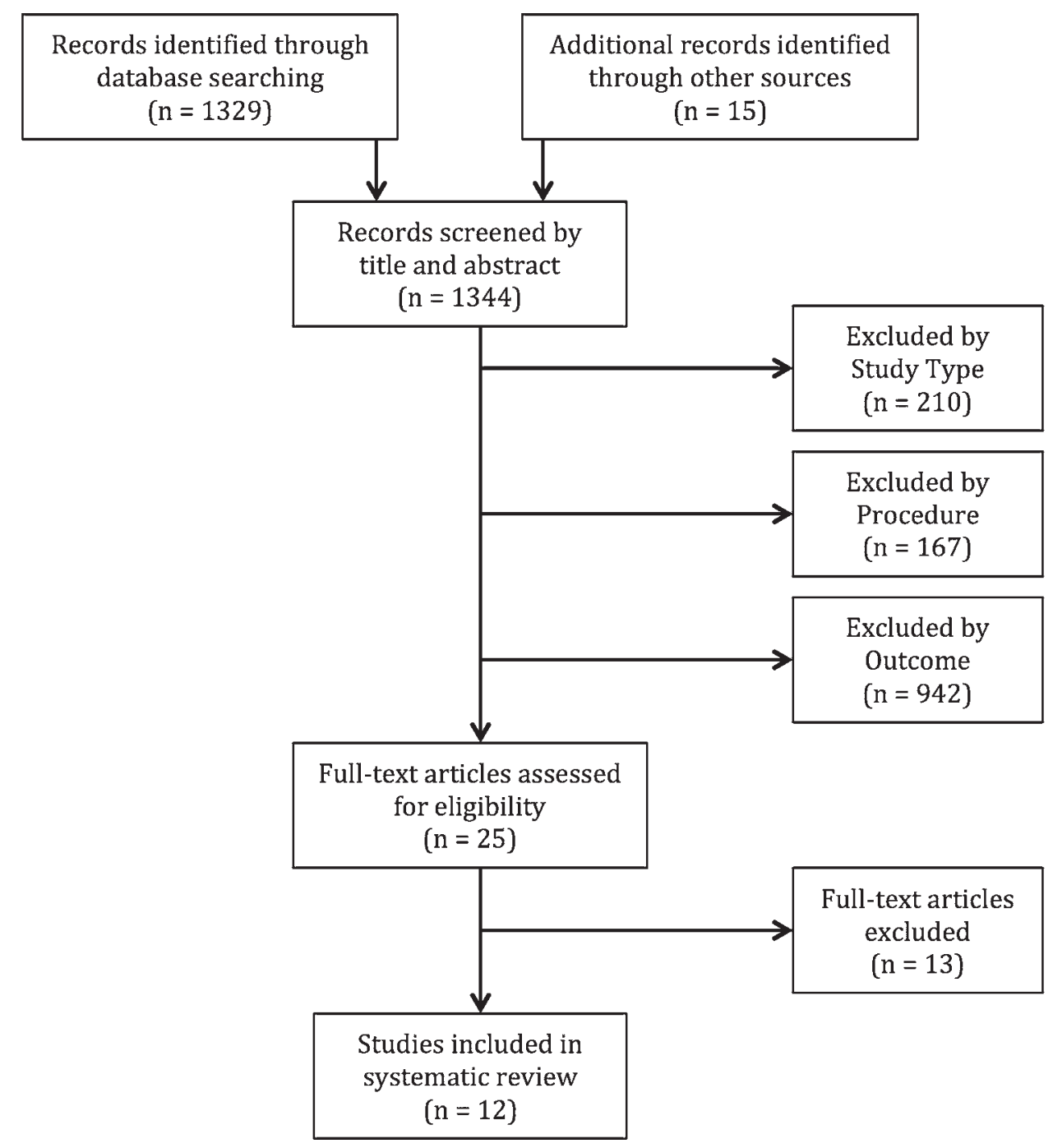

FIG. 2. A PRISMA flow diagram showing the flow of information through the different phases of the systematic review.

whereas the 3 remaining studies ${ }^{6,47,50}$ stated reasons for readmission with no analysis of their significance. Analytical methods used to examine predictors of readmission included univariate analyses, $, 9,16,34,36,42,43,52$ multivariate logistic regression, , $, 16,32,36,38,42,52$ and bivariate analyses using the Welch t-test and Pearson chi-square test. ${ }^{32,38}$ None of the articles reported power analyses to determine if their study had a sufficient sample size to detect an effect, if an effect was present.

Tables 2-4 present a summary of the characteristics of patients that have been shown to be predictive of readmission. There was strong consistency in several patient and procedural factors, such as age (see Table 2); however, results for sex and race were inconsistent between studies. Although 2 studies demonstrated that age was a significant factor in predicting readmission, ${ }^{32,34}$ the majority of the studies reported nonsignificant results., $16,34,36,38$ Sex was found to be a significant and important predicting factor in $2^{32,34}$ of the $6^{9,16,32,34,36,38}$ studies that examined it; males were more likely to be readmitted in the hospital after neurosurgery than females. Race was examined by 5 of the 12 studies as a possible readmissions predictor. Marcus et al. ${ }^{32}$ found that African American and Hispanic patients were more likely to be readmitted. Nuño et al. ${ }^{36}$ found that nonwhite patients were at greater risk for 30-day readmission after neurosurgery. Moghavem et al. ${ }^{34}$ reported that black or Hispanic ethnicity were predictors of readmission after neoplasm surgery, and that black ethnicity was found to be a significant predictor of readmission for patients with vascular conditions. Two studies reported that race was not a significant predictor in hospital readmission after neurosurgery. ${ }^{9,16}$ Other patient and procedural factors that were found to be consistently nonsignificant in the studies we reviewed were household income, ${ }^{9,36}$ tumor size, ${ }^{16,36}$ procedure length, $, 38,52$ and extent of resection..$^{16,36}$

Several comorbidities were found to predict readmission after neurosurgery (Table 3). Three studies found that having chronic obstructive pulmonary disease, diabetes mellitus, or congestive heart failure were risk factors for hospital readmission. ${ }^{32,34,38}$ Interestingly, Moghavem et al. ${ }^{34}$ and Rambachan et al. ${ }^{38}$ showed that alcohol abuse was not a significant predictor of hospital readmission af- 


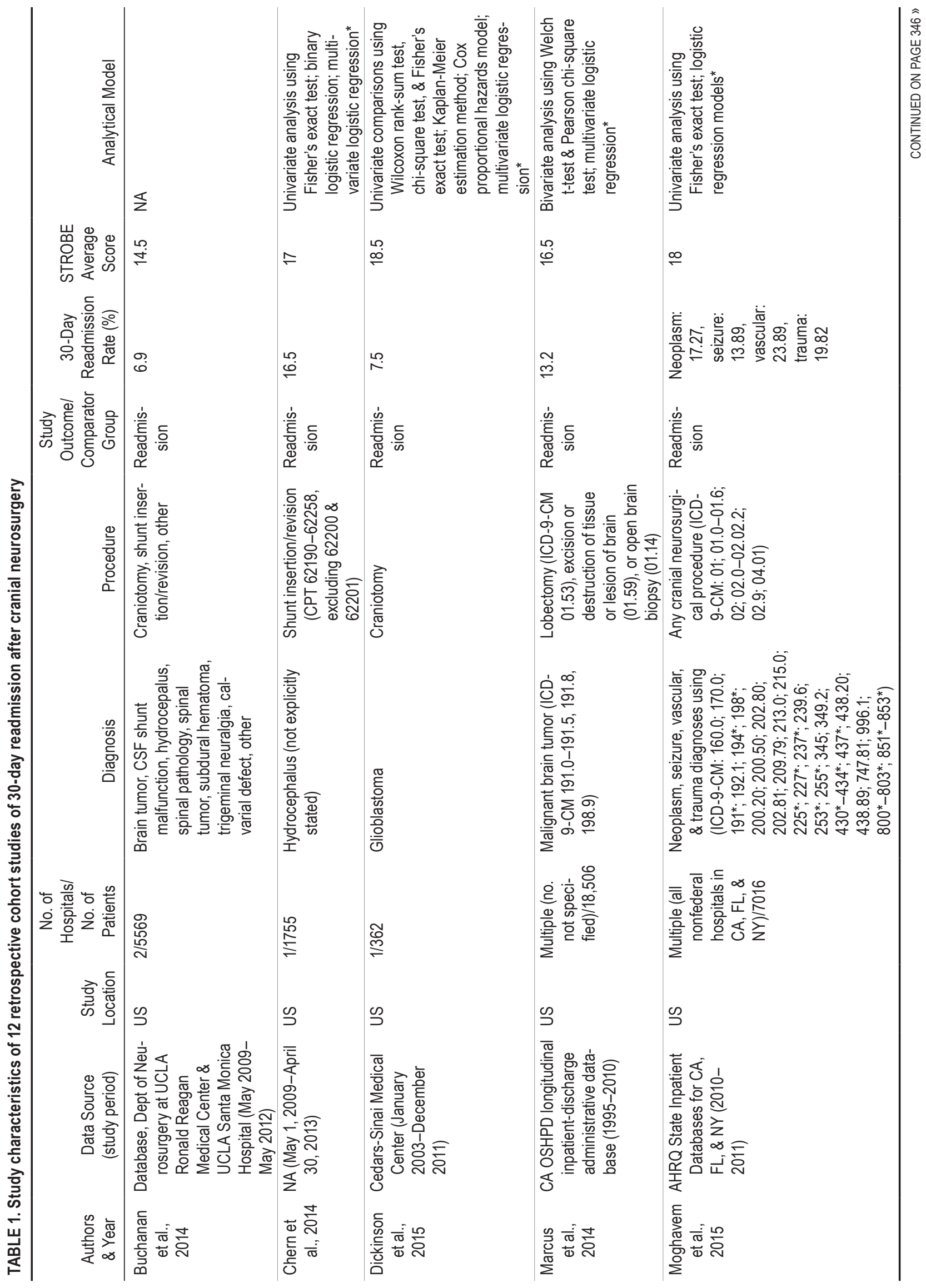




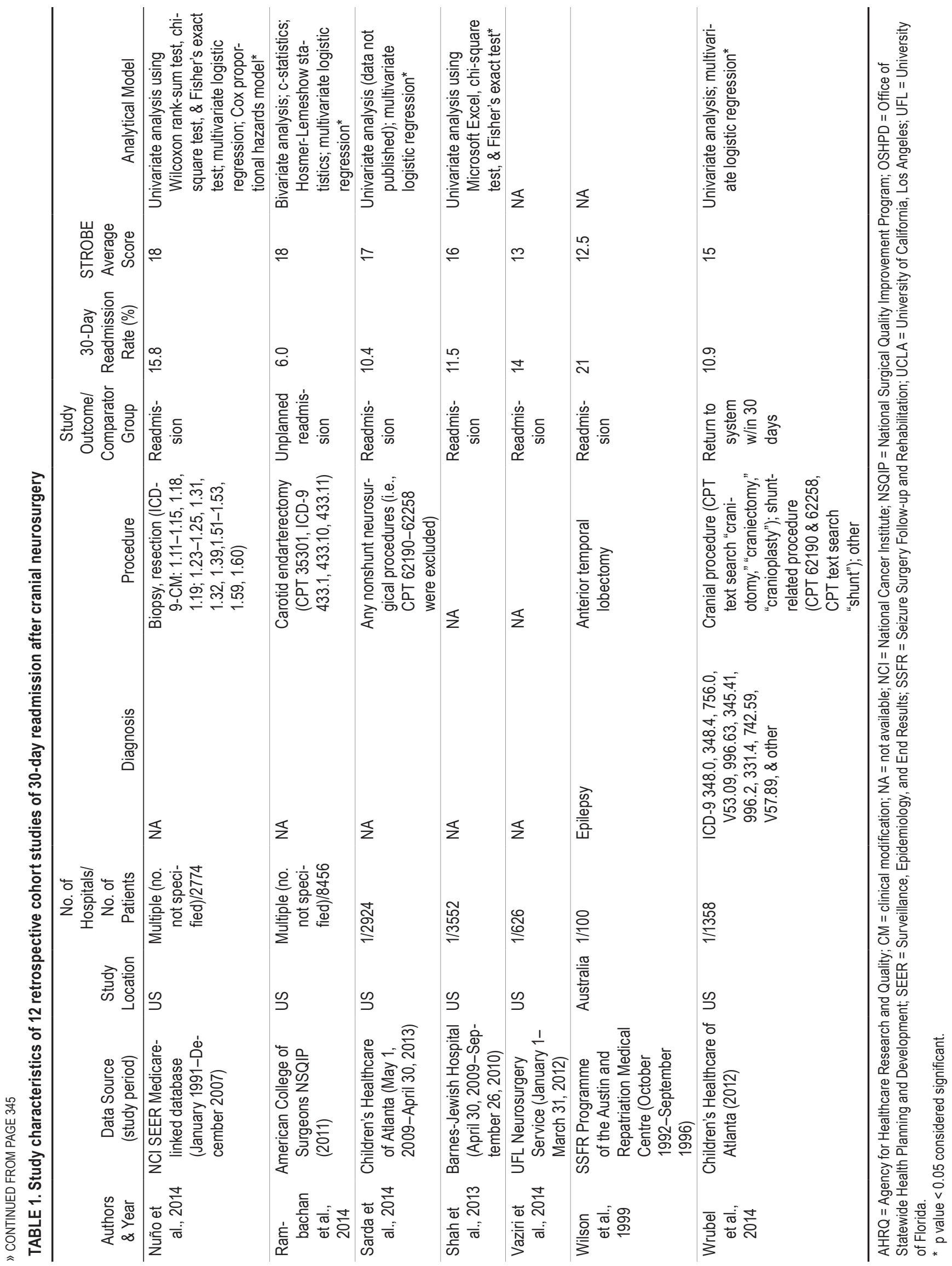


TABLE 2. Contributions of patient characteristics (patient and procedural factors)

\begin{tabular}{|c|c|c|c|c|c|c|c|c|c|c|c|}
\hline \multirow[b]{2}{*}{ Authors \& Year } & \multicolumn{7}{|c|}{ Patient Factors } & \multicolumn{4}{|c|}{ Procedural Factors } \\
\hline & Age & Sex & Race & $\begin{array}{l}\text { Marital } \\
\text { Status }\end{array}$ & $\begin{array}{l}\text { Residence } \\
\text { Location }\end{array}$ & $\begin{array}{l}\text { Household } \\
\text { Income }\end{array}$ & $\begin{array}{l}\text { Tumor } \\
\text { Size }\end{array}$ & Type & $\begin{array}{l}\text { Major/ } \\
\text { Minor }\end{array}$ & Length & EOR \\
\hline Buchanan et al., 2014 & $x$ & $x$ & 0 & 0 & 0 & 0 & 0 & $x$ & $x$ & 0 & 0 \\
\hline Chern et al., 2014 & NS & 0 & NS & 0 & 0 & NS & 0 & NS & 0 & NS & 0 \\
\hline Dickinson et al., 2015 & NS & NS & NS & 0 & 0 & 0 & NS & 0 & 0 & 0 & NS \\
\hline Marcus et al., 2014 & S & $\mathrm{s}$ & S & 0 & 0 & 0 & 0 & 0 & 0 & 0 & 0 \\
\hline Moghavem et al., $2015^{\star}$ & $\mathrm{NS}^{\mathrm{a}, \mathrm{c},} \mathrm{S}^{\mathrm{b}, \mathrm{d}}$ & $\mathrm{S}^{\mathrm{a}-\mathrm{c}}, \mathrm{NS}^{\mathrm{d}}$ & $S^{a, c}, N S^{b, d}$ & $\mathrm{O}^{\mathrm{a}-\mathrm{d}}$ & $N S^{a, b}, S^{c, d}$ & $\mathrm{O}^{\mathrm{a}-\mathrm{d}}$ & $\mathrm{O}^{\mathrm{a}-\mathrm{d}}$ & $\mathrm{O}^{\mathrm{a}-\mathrm{d}}$ & $\mathrm{O}^{a-d}$ & $\mathrm{O}^{\mathrm{a}-\mathrm{d}}$ & $\mathrm{O}^{\mathrm{a}-\mathrm{d}}$ \\
\hline Nuño et al., 2014 & NS & NS & S & NS & 0 & NS & NS & 0 & 0 & 0 & NS \\
\hline Rambachan et al., 2014 & NS & NS & 0 & 0 & 0 & 0 & 0 & 0 & 0 & NS & 0 \\
\hline Sarda et al., 2014 & 0 & 0 & 0 & 0 & 0 & 0 & 0 & $\mathrm{x}$ & $\mathrm{s}$ & 0 & 0 \\
\hline Shah et al., 2013 & $x$ & $x$ & $x$ & 0 & 0 & 0 & 0 & 0 & 0 & 0 & 0 \\
\hline Vaziri et al., 2014 & 0 & 0 & 0 & 0 & 0 & 0 & 0 & 0 & 0 & 0 & 0 \\
\hline Wilson et al., 1999 & $\mathrm{X}$ & $\mathrm{X}$ & 0 & $\mathrm{X}$ & 0 & 0 & 0 & 0 & 0 & 0 & 0 \\
\hline Wrubel et al., 2014 & NS & 0 & 0 & 0 & 0 & 0 & 0 & $\mathrm{~s}$ & 0 & NS & 0 \\
\hline
\end{tabular}

$\mathrm{EOR}=$ extent of resection; $\mathrm{NS}=$ not statistically significant; $\mathrm{O}=$ the variable was not assessed or considered in the model; $S=$ the variable was found to be statistically significant; $\mathrm{X}=$ the variable was considered in the model but statistical significance was not reported or was unclear.

* Reported 4 separate sets of data-for patients with neoplasm (a), seizure (b), vascular condition (c), and trauma (d).

ter neurosurgery. There was no consistency in the findings for hypertension and obesity as significant predictors of readmission. Marcus et al..$^{32}$ and Moghavem et al..$^{34}$ found that these 2 comorbidities were positively correlated with readmission rates; however, results reported by Rambachan et al..$^{38}$ showed no such correlation.

Six studies examined length of stay (LOS) at index admission as a predictor for hospital readmission (Table 4). Five of these found it to be a significant predictor; $9,32,36,42,52$ specifically, 4 of the 5 studies showed a positive correlation between LOS and readmission rates., ${ }^{9,32,36,42}$ In addition, the significance of discharge disposition was demonstrated by Dickinson et al. ${ }^{16}$ and Nuño et al. ${ }^{36}$ Furthermore, Chern et al. ${ }^{9}$ reported that being a Medicaid payee was a risk factor for hospital readmission. Marcus et al. ${ }^{32}$ found that having Medi-Cal insurance increased the risk of readmission when compared with having private insurance. Moghavem et al. ${ }^{34}$ found that being a Medicare or Medicaid payee as a patient with a neoplasm or a vascular condition was a significant predictor for hospital readmission compared with being a private insurance payee. Three other studies, however, found that insurance coverage was not a significant predictor. ${ }^{34,43,42}$ Additionally, Chern et al. ${ }^{9}$ and Sarda et al. ${ }^{42}$ found that index admission through the emergency department and neonatal ICU increased the likelihood of being readmitted. Moghavem et al. ${ }^{34}$ found admission type at index admission to be a significant predictor for hospital readmission among patients with neoplasm and seizure di-

TABLE 3. Contributions of patient characteristics (comorbidities)

\begin{tabular}{|c|c|c|c|c|c|c|c|c|c|}
\hline \multirow[b]{2}{*}{ Authors \& Year } & \multicolumn{9}{|c|}{ Comorbidities } \\
\hline & Hypertension & $\begin{array}{c}\text { Tobacco Use } \\
\text { Disorder/Smoking }\end{array}$ & COPD & $\begin{array}{l}\text { Diabetes } \\
\text { Mellitus }\end{array}$ & $\begin{array}{l}\text { Obesity \& } \\
\text { Overweight }\end{array}$ & $\mathrm{CHF}$ & $\begin{array}{l}\text { Renal Disease/ } \\
\text { Failure }\end{array}$ & $\begin{array}{c}\text { Liver } \\
\text { Disease }\end{array}$ & $\begin{array}{l}\text { Alcohol } \\
\text { Abuse }\end{array}$ \\
\hline Buchanan et al., 2014 & 0 & 0 & 0 & 0 & 0 & 0 & 0 & 0 & 0 \\
\hline Chern et al., 2014 & 0 & 0 & 0 & 0 & 0 & 0 & 0 & 0 & 0 \\
\hline Dickinson et al., 2015 & 0 & 0 & 0 & 0 & 0 & 0 & 0 & 0 & 0 \\
\hline Marcus et al., 2014 & $S$ & NS & $S$ & $S$ & $S$ & S & NS & $S$ & 0 \\
\hline Moghavem et al., $2015^{*}$ & $N S^{a-c}, S^{d}$ & $\mathrm{O}^{\mathrm{a}-\mathrm{d}}$ & $N S^{a, c}, O^{b}, S^{d}$ & $S^{a, c}, N S^{b, d}$ & $\mathrm{O}^{\mathrm{a}, \mathrm{b}, \mathrm{d}}, \mathrm{S}^{\mathrm{c}}$ & $\mathrm{S}^{\mathrm{a}, \mathrm{c}, \mathrm{d}}, \mathrm{NS} \mathrm{S}^{\mathrm{b}}$ & $\mathrm{O}^{\mathrm{a}, \mathrm{b}, \mathrm{d}, \mathrm{S}^{\mathrm{c}}}$ & 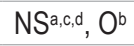 & $\mathrm{O}^{\mathrm{a}-\mathrm{c}}, \mathrm{NS}^{\mathrm{d}}$ \\
\hline Nuño et al., 2014 & 0 & 0 & 0 & 0 & 0 & 0 & 0 & 0 & 0 \\
\hline Rambachan et al., 2014 & NS & NS & $S$ & $S$ & NS & $S$ & 0 & 0 & NS \\
\hline Sarda et al., 2014 & 0 & 0 & 0 & 0 & 0 & 0 & 0 & 0 & 0 \\
\hline Shah et al., 2013 & 0 & 0 & 0 & 0 & 0 & 0 & 0 & 0 & 0 \\
\hline Vaziri et al., 2014 & 0 & 0 & 0 & 0 & 0 & 0 & 0 & 0 & 0 \\
\hline Wilson et al., 1999 & 0 & 0 & 0 & 0 & 0 & 0 & 0 & 0 & 0 \\
\hline Wrubel et al., 2014 & 0 & 0 & 0 & 0 & 0 & 0 & 0 & 0 & 0 \\
\hline
\end{tabular}

$\mathrm{CHF}=$ congestive heart failure; $\mathrm{COPD}=$ chronic obstructive pulmonary disease; $\mathrm{NS}=$ not statistically significant; $\mathrm{O}=$ the variable was not assessed or considered in the model; $\mathrm{S}=$ the variable was found to be statistically significant.

* Reported 4 separate sets of data_for patients with neoplasm (a), seizure (b), vascular condition (c), and trauma (d). 
TABLE 4. Contributions of patient characteristics (health system factors)

\begin{tabular}{|c|c|c|c|c|c|}
\hline \multirow[b]{2}{*}{ Authors \& Year } & \multicolumn{5}{|c|}{ Health System Factors } \\
\hline & $\begin{array}{c}\text { Expected Primary } \\
\text { Payer }\end{array}$ & $\begin{array}{l}\text { Admission Type at } \\
\text { Index Admission }\end{array}$ & $\begin{array}{l}\text { LOS (index } \\
\text { admission) }\end{array}$ & $\begin{array}{c}\text { LOS } \\
\text { (readmission) }\end{array}$ & $\begin{array}{l}\text { Discharge } \\
\text { Disposition }\end{array}$ \\
\hline Buchanan et al., 2014 & 0 & $x$ & $x$ & 0 & 0 \\
\hline Chern et al., 2014 & $S$ & S & $S$ & 0 & 0 \\
\hline Dickinson et al., 2015 & 0 & NS & NS & 0 & $S$ \\
\hline Marcus et al., 2014 & $S$ & 0 & $S$ & 0 & 0 \\
\hline Moghavem et al., $2015^{\star}$ & $S^{a, c, d}, N S^{b}$ & $S^{a, b}, N S^{c, d}$ & $\mathrm{O}^{\mathrm{a}-\mathrm{d}}$ & $X^{a-d}$ & $\mathrm{O}^{\mathrm{a}-\mathrm{d}}$ \\
\hline Nuño et al., 2014 & 0 & NS & S & 0 & S \\
\hline Rambachan et al., 2014 & 0 & 0 & 0 & 0 & 0 \\
\hline Sarda et al., 2014 & 0 & S & S & 0 & 0 \\
\hline Shah et al., 2013 & NS & 0 & 0 & 0 & 0 \\
\hline Vaziri et al., 2014 & 0 & 0 & 0 & 0 & $x$ \\
\hline Wilson et al., 1999 & 0 & 0 & 0 & 0 & 0 \\
\hline Wrubel et al., 2014 & NS & NS & $S$ & 0 & 0 \\
\hline
\end{tabular}

agnoses, and it was not a significant predictor for patients with vascular conditions and trauma. On the other hand, Dickinson et al., ${ }^{16}$ Nuño et al., ${ }^{36}$ and Wrubel et al. ${ }^{52}$ did not find admission type at index admission to be a significant predictor.

Reasons for readmission and complications presenting after surgery are listed in Tables 5 and 6 , and were identified by all but one study. ${ }^{42}$ Sarda et al., who focused on pediatric cases, however, found that a stay at the ICU during index admission was a predictor of readmission. Surgical and wound complications, including surgical site and wound infections, were frequent causes for readmission. $6,9,16,32,38,43,47,50,52$ Rambachan et al. ${ }^{38}$ reported surgical site infection as the most significant predictor of readmission when compared with patients who were not readmitted after carotid endarterectomy. Both Marcus et al. ${ }^{32}$ and Rambachan et al. found sepsis and septicemia as significant predictors of readmission for patients with neoplasm and vascular conditions. Rates of urinary tract infection were associated with higher rates of readmission in patients with vascular conditions, ${ }^{38}$ and with lower odds of readmission following surgery for tumors. ${ }^{32}$ Pulmonary embolism (PE) and deep venous thrombosis (DVT) ${ }^{6,16,32,34,36,38,43}$ were significant predictors of readmission following surgery for vascular conditions ${ }^{38}$ and tumors. ${ }^{32}$ Cardiac arrest and myocardial infarction were found to be significant predic-

TABLE 5. Surgical and medical complications during hospital stay and readmission

\begin{tabular}{|c|c|c|c|c|c|c|c|c|c|}
\hline \multirow[b]{2}{*}{ Authors \& Year } & \multirow[b]{2}{*}{$\begin{array}{c}\text { Infectious } \\
\text { Complications }\end{array}$} & \multicolumn{5}{|c|}{ Surgical Complications } & \multicolumn{3}{|c|}{ Medical Complications } \\
\hline & & $\begin{array}{l}\text { Surgical } \\
\text { Wound }\end{array}$ & $\begin{array}{c}\text { SSI/ } \\
\text { Wound } \\
\text { Infection }\end{array}$ & $\begin{array}{c}\text { Shunt } \\
\text { Malfunction/ } \\
\text { Revision }\end{array}$ & $\begin{array}{c}\text { Wound } \\
\text { Dehiscence/ } \\
\text { Revision }\end{array}$ & $\begin{array}{c}\text { Sepsis/ } \\
\text { Septic Shock/ } \\
\text { Septicemia }\end{array}$ & Cardiac & UTI & Pneumonia \\
\hline Buchanan et al., 2014 & 0 & $x$ & $x$ & 0 & 0 & 0 & 0 & $x$ & $x$ \\
\hline Chern et al., 2014 & 0 & 0 & 0 & $X$ & $x$ & 0 & 0 & 0 & 0 \\
\hline Dickinson et al., 2015 & $X$ & 0 & $X$ & 0 & 0 & 0 & $x$ & $X$ & 0 \\
\hline Marcus et al., 2014 & $S$ & $S$ & 0 & 0 & 0 & $S$ & 0 & $S$ & 0 \\
\hline Moghavem et al., 2015* & $X^{a-d}$ & 0 & 0 & 0 & 0 & $X^{a, c, d}$ & 0 & $X^{c, d}$ & $X^{a, c, d}$ \\
\hline Nuño et al., 2014 & $x$ & 0 & 0 & 0 & 0 & 0 & $x$ & 0 & 0 \\
\hline Rambachan et al., 2014 & 0 & 0 & $S$ & 0 & NS & $S$ & $S$ & $S$ & $S$ \\
\hline Sarda et al., 2014 & 0 & 0 & 0 & 0 & 0 & 0 & 0 & 0 & 0 \\
\hline Shah et al., 2013 & 0 & $x$ & $x$ & 0 & $x$ & 0 & 0 & $x$ & $x$ \\
\hline Vaziri et al., 2014 & 0 & 0 & $x$ & $x$ & $x$ & 0 & $x$ & $x$ & 0 \\
\hline Wilson et al., 1999 & 0 & $X$ & 0 & 0 & 0 & 0 & 0 & 0 & 0 \\
\hline Wrubel et al., 2014 & 0 & $x$ & 0 & 0 & 0 & 0 & 0 & 0 & 0 \\
\hline
\end{tabular}

NS = not statistically significant; $\mathrm{O}=$ the variable was not assessed or considered in the model; $\mathrm{S}=$ the variable was found to be statistically significant; $\mathrm{SSI}=$ surgical site infection; UTI = urinary tract infection; $\mathrm{X}=$ the variable was considered in the model but statistical significance was not reported or was unclear.

* Reported 4 separate sets of data-for patients with neoplasm (a), seizure (b), vascular condition (c), and trauma (d). 
TABLE 6. Medical complications during hospital stay and readmission

\begin{tabular}{|c|c|c|c|c|c|c|c|c|c|}
\hline \multirow[b]{3}{*}{ Authors \& Year } & \multicolumn{9}{|c|}{ Medical Complications } \\
\hline & \multicolumn{3}{|c|}{$\begin{array}{c}\text { Thromboembolic } \\
\text { Complications }\end{array}$} & \multicolumn{6}{|c|}{ Neurological Complications } \\
\hline & General & PE & DVT & General & CVA/Stroke & Hydrocephalus & Sz \& Convulsive Disorder & Hemorrhage & CSF Leak \\
\hline Buchanan et al., 2014 & 0 & $X$ & $x$ & $X$ & 0 & $X$ & $X$ & 0 & $X$ \\
\hline Chern et al., 2014 & 0 & 0 & 0 & 0 & 0 & 0 & 0 & 0 & 0 \\
\hline Dickinson et al., 2015 & $X$ & $X$ & $x$ & $X$ & 0 & $X$ & $x$ & $x$ & 0 \\
\hline Marcus et al., 2014 & 0 & $S$ & $S$ & 0 & 0 & $S$ & $S$ & 0 & 0 \\
\hline Moghavem et al., $2015^{*}$ & 0 & $X^{a-c}$ & $X^{a, b}$ & $x^{a}$ & 0 & $X^{a, b}$ & $X^{b, d}$ & $X^{c, d}$ & 0 \\
\hline Nuño et al., 2014 & $x$ & 0 & 0 & $X$ & 0 & 0 & 0 & 0 & 0 \\
\hline Rambachan et al., 2014 & 0 & $S$ & $S$ & 0 & $S$ & 0 & 0 & 0 & 0 \\
\hline Sarda et al., 2014 & 0 & 0 & 0 & 0 & 0 & 0 & 0 & 0 & 0 \\
\hline Shah et al., 2013 & $X$ & 0 & 0 & 0 & $x$ & $x$ & 0 & 0 & $x$ \\
\hline Vaziri et al., 2014 & 0 & 0 & 0 & 0 & 0 & $x$ & $x$ & 0 & $x$ \\
\hline Wilson et al., 1999 & 0 & 0 & 0 & 0 & 0 & 0 & $x$ & 0 & 0 \\
\hline Wrubel et al., 2014 & 0 & 0 & 0 & 0 & 0 & 0 & 0 & 0 & 0 \\
\hline
\end{tabular}

CVA = cerebrovascular accident; $\mathrm{O}=$ the variable was not assessed or considered in the model; $\mathrm{S}=$ the variable was found to be statistically significant; $\mathrm{Sz}=$ seizure; $\mathrm{X}$ $=$ the variable was considered in the model but statistical significance was not reported or was unclear.

* Reported 4 separate sets of data-for patients with neoplasm (a), seizure (b), vascular condition (c), and trauma (d).

tors of readmission in patients with vascular conditions in 1 of the 12 studies reviewed. ${ }^{38}$

The most frequent reasons for readmission were related to neurological complications $\mathrm{s}^{30}$ including seizures and convulsive disorders, ${ }^{6,16,32,34,47,50}$ hydrocephalus, ${ }^{6,16,32,34,43,47}$ and hemorrhage. ${ }^{16,34}$ After surgery for vascular conditions, cerebrovascular accident and/or stroke predicted readmission, whereas coma and peripheral nerve complications did not. ${ }^{38}$ Six studies also found that seizures were frequent causes for readmission following neurosurgery for neoplasm, seizure, and trauma. ${ }^{6,16,32,34,47,50}$ Finally, 30-day readmission was a significant predictor of death in patients surviving brain tumor surgeries ${ }^{16}$ and increased the risk of dying by $30 \%$ for patients with glioblastoma. ${ }^{36}$

\section{Discussion}

We found considerable variability, ranging from $6.0 \%$ to $23.89 \%$, in the 30 -day readmission rates for neurosurgical cranial procedures. Factors found to be predictive of readmission were also notably different between studies. This variance is related to a number of different issues. First, study characteristics between these reports differed in selection criteria based on procedures and diagnoses. Second, coding systems for diagnoses and procedures also differed between studies; some studies used CPT, 9,38,42,52 others used ICD-9,32,34,36,38,52 and yet others did not use a coding system. ${ }^{6,16,43,47,50}$ Between the 2 studies that assessed only patients with glioblastoma, ${ }^{16,36}$ an $8.3 \%$ discrepancy in readmission rates ( $7.5 \%$ vs $15.8 \%$ ) was observed, which may have resulted from differences between the studies' selection of patients' procedures. Future investigations may address this discrepancy by using standardized patient coding processes to increase comparability between studies.

The differences in readmission rates can also be accounted for by discrepancies in the definition of readmis- sion between studies. Readmission varied in definition by readmission type (whether planned or unplanned), the type of services to which patients were readmitted (whether neurosurgical or general), and whether all patients were recorded as readmitted or only as inpatients. For example, Dickinson et al. ${ }^{16}$ used same-hospital readmission rates, whereas Marcus et al. ${ }^{32}$ and Moghavem et al. ${ }^{34}$ captured patients readmitted to nonindex and index admission sites. Moghavem et al. found that less than $43 \%$ of patients were readmitted to the site of the index procedure, regardless of diagnosis group, demonstrating the importance of capturing from both index and nonindex sites. Several studies urge caution with respect to same-hospital readmission metrics because their use can produce artificially lower readmission rates for hospitals whose patients are readmitted elsewhere, resulting in a bias in favor of said hospitals. ${ }^{15,20,35}$ Studies that have proposed the use of a general definition for readmission are scarce in the current literature. ${ }^{40}$ Therefore, future studies should try to include all hospital readmission data sources available in their comparisons to avoid these limitations.

Most $^{9,16,36,38,52}$ of the studies found that age was not a predictor of 30-day readmission after neurosurgery procedures. This finding is surprising because age has been found to be positively associated with mortality and complication rates in spine surgery ${ }^{44,49}$ as well as many other surgical procedures. ${ }^{22,26,43}$ Nevertheless, our results regarding cranial neurosurgery suggest that resource allocation for quality of care improvement should depend on comorbidities and complications to a greater extent than age.

Although some inconsistency was found between studies, a patient's race was generally found to be an important factor in 30-day readmission. Being African American, Hispanic, or nonwhite was found to be a risk factor by $3^{32,34,36}$ of the 5 studies $^{9,16,32,34,36}$ that evaluated the role of race and readmission. This finding agrees with the conclu- 
sion that there are racial disparities in patient outcomes after craniotomy for tumor. Previous literature has shown that African American patients are significantly more prone to fluid or electrolyte and renal or urinary diseases compared with white patients. ${ }^{12}$ This may provide an explanation for the underlying cause of the association between race and readmission. Other social factors, such as socioeconomic status, can influence the extent of a patient's insurance coverage. In particular, we found that Medicare, Medicaid, and Medi-Cal increased risk of readmission in neurosurgical patients. ${ }^{9,32,34}$ However, we investigated an equal number of studies that did not find insurance coverage to be significant. This finding is corroborated by past studies in other surgical disciplines, which do not form a consensus on the impact of insurance type on readmission rate. ${ }^{3,39,45}$ Evidently, additional studies that examine the role of social factors in defining quality outcomes, such as 30-day readmission, are required.

Not surprisingly, our review shows that sick patients tend to get readmitted. Having diabetes mellitus or congestive heart failure was consistently found to be a risk factor. ${ }^{32,34,38}$ This supports past studies that showed a significant association between diabetes or hypertension and poor postoperative improvement after various procedures. ${ }^{1,5,10,21,32,46}$

Most of the studies that examined LOS at index admission found that it was positively correlated with readmission. ${ }^{9,32,36,42}$ Wrubel et al. ${ }^{52}$ found a negative correlation between LOS and rate of readmission; however, after running a secondary analysis with the return to system based on day of discharge rather than day of surgery, they determined that no significant correlation was present. This further substantiates the consistent finding within the examined studies that LOS is positively correlated with readmission rates. Importantly, LOS correlates with but does not cause increases in readmission rates, because the relationship between LOS and readmission rates is confounded by preexisting underlying illness or in-hospital complications, which are typically the true causes of readmission. ${ }^{5,8,11}$

Our study not only explored predictors of readmission, but also the reasons for readmission. Surgical and wound complications, including infectious complications, were two of the major reasons for hospital readmission. ${ }^{6,9,16,32,34,36,38 \text {, }}$ 43,47,52 Effective preoperative, intraoperative, and postoperative measures of prophylaxis are available in other disciplines. ${ }^{19,41}$ Since these complications can be prevented by good technique and prophylactic antibiotics, systematic attempts at reducing these adverse events hold promise, particularly for patients who are prone to infection, such as those with diabetes mellitus. ${ }^{16,34}$

Our review also showed that postoperative complications significantly predicted 30 -day readmission. ${ }^{32,38} \mathrm{~Pa}$ tients who suffered seizures $6,16,32,34,47,50,52$ and hydrocepha$\operatorname{lus}^{6,16,32,34,43,47}$ had higher rates of readmission. Similar to Kassin et al., ${ }^{25}$ who studied general surgical patients, we found that patients with pulmonary complications such as pneumonia, unplanned reintubation, mechanical ventilation for more than 48 hours, and acute respiratory failure had an increased risk of readmission. ${ }^{38}$ A review of patients who underwent craniotomy for meningioma identi- fies older patients and those undergoing longer procedures as being at higher risk of acquiring postoperative pneumonia. ${ }^{37}$ Efforts should be put forward to establish all populations at risk and provide preventative measures, including patient education. ${ }^{7,51}$ The importance of postoperative complications has been repeatedly shown by a number of studies across a variety of surgical disciplines. ${ }^{6,13,25,23,36,50}$ Thus, continued concerted attempts at reducing postoperative complications are imperative in any quality improvement initiative.

Our review showed that DVT and PE were also 2 important preventable causes of 30-day readmission. ${ }^{6,16,32,34,38}$ In spite of this, the prevention of venous thromboembolism (VTE) is difficult in patients undergoing brain surgery. ${ }^{14,31}$ The risks of anticoagulation therapy (particularly intracranial hemorrhage) need to be weighed against its benefits. ${ }^{4,14,16}$ Although high-risk groups such as those with prior DVT, those with glioblastoma multiforme, and those with an immobile limb exist, as of yet no clearly safe time period for anticoagulation has been defined. For example, in our review, Moghavem et al. ${ }^{34}$ showed that patients with diagnoses of vascular conditions and trauma have higher rates of hemorrhage, therefore making them higher-risk candidates for VTE prophylaxis. In contrast, other studies of patients with traumatic brain injury showed that current chemoprophylactic regimens provide a relatively high level of protection against VTE events, while not increasing risks of intracranial bleeding. ${ }^{17,28,33}$ Defining these criteria with statistical rigor within specific subgroups will require large multiinstitutional randomized controlled studies.

\section{Limitations and Future Work}

Although we identified 12 studies of postneurosurgery hospital readmission, given the proportion of conditions treated by neurosurgeons (e.g., trauma, stroke, and so on), more studies are required before we can generalize these results. Additionally, publication bias may have reduced the number of studies presenting nonsignificant results in the factors related to readmission. ${ }^{18}$ We found considerable variability in diagnoses, procedures, sample sizes, geographic location, and analytical methods. To improve comparability of causes and rates of readmission between studies, and of methods by which to reduce them, it is important that future studies follow a standardized methodology when assessing readmission rates. This review may serve as a guide for future variables inclusion. Because nearly all of the papers are from the US, future work should include studies from Canada and other developed and nondeveloped countries to gather a more holistic view of the causes for readmission, particularly in countries with different forms of health care financing. Prospectively collected surveillance data should form the basis of our work in the future, which may highlight the importance of organized neurosurgery through groups like the NeuroPoint Alliance.

\section{Conclusions}

Research that investigates readmission rates in patients who undergo cranial neurosurgery is scarce. Our review shows that there are patient factors, such as race, comorbidities, neurosurgical diagnoses, and procedures that are 
important in predicting readmission. Moreover, we demonstrated that social factors including place of residence and insurance coverage are also predictive. Our review highlights the importance of having preventive systems in place to minimize postoperative complications. To achieve this, a framework that includes a consideration of the patient, the patient's social environment, community, and resources, and the whole hospital and surgical team and its resources is warranted. The review is limited by the small number of studies reported in neurosurgery readmission to date. Opportunities for preventive measures must be considered before, during, and after the surgical procedure. Working toward reducing 30-day readmission would be a reachable goal for many neurosurgical communities aiming for improved quality of care.

\section{Acknowledgments}

We thank David Lightfoot, librarian, for assisting with the conception and design of the literature search.

\section{References}

1. Appaduray SP, Lo P: Effects of diabetes and smoking on lumbar spinal surgery outcomes. J Clin Neurosci 20:17131717,2013

2. Berenson RA, Paulus RA, Kalman NS: Medicare's readmissions-reduction program-a positive alternative. N Engl J Med 366:1364-1366, 2012

3. Bradley EH, Yakusheva O, Horwitz LI, Sipsma H, Fletcher J: Identifying patients at increased risk for unplanned readmission. Med Care 51:761-766, 2013

4. Browd SR, Ragel BT, Davis GE, Scott AM, Skalabrin EJ, Couldwell WT: Prophylaxis for deep venous thrombosis in neurosurgery: a review of the literature. Neurosurg Focus 17(4):E1, 2004

5. Bucerius J, Gummert JF, Walther T, Doll N, Falk V, Onnasch JF, et al: Impact of diabetes mellitus on cardiac surgery outcome. Thorac Cardiovasc Surg 51:11-16, 2003

6. Buchanan CC, Hernandez EA, Anderson JM, Dye JA, Leung M, Buxey F, et al: Analysis of 30-day readmissions among neurosurgical patients: surgical complication avoidance as key to quality improvement. J Neurosurg 121:170-175, 2014

7. Cassidy MR, Rosenkranz P, McCabe K, Rosen JE, McAneny D: I COUGH: reducing postoperative pulmonary complications with a multidisciplinary patient care program. JAMA Surg 148:740-745, 2013

8. Chang JK, Calligaro KD, Lombardi JP, Dougherty MJ: Factors that predict prolonged length of stay after aortic surgery. J Vasc Surg 38:335-339, 2003

9. Chern JJ, Bookland M, Tejedor-Sojo J, Riley J, Shoja MM, Tubbs RS, et al: Return to system within 30 days of discharge following pediatric shunt surgery. J Neurosurg Pediatr 13:525-531, 2014

10. Clough RA, Leavitt BJ, Morton JR, Plume SK, Hernandez F, Nugent W, et al: The effect of comorbid illness on mortality outcomes in cardiac surgery. Arch Surg 137:428-433, 2002

11. Collins TC, Daley J, Henderson WH, Khuri SF: Risk factors for prolonged length of stay after major elective surgery. Ann Surg 230:251-259, 1999

12. Curry WT Jr, Carter BS, Barker FG II: Racial, ethnic, and socioeconomic disparities in patient outcomes after craniotomy for tumor in adult patients in the United States, 19882004. Neurosurgery 66:427-438, 2010

13. Cusimano MD, Pshonyak I, Lee MY, Ilie G: Causes of 30day readmission after neurosurgery of the spine. J Neurosurg Spine 9:1-10, 2015
14. Danish SF, Burnett MG, Ong JG, Sonnad SS, MaloneyWilensky E, Stein SC: Prophylaxis for deep venous thrombosis in craniotomy patients: a decision analysis. Neurosurgery 56:1286-1294, 2005

15. Davies SM, Saynina O, McDonald KM, Baker LC: Limitations of using same-hospital readmission metrics. Int J Qual Health Care 25:633-639, 2013

16. Dickinson H, Carico C, Nuño M, Mukherjee D, Ortega A, Black KL, et al: Unplanned readmissions and survival following brain tumor surgery. J Neurosurg 122:61-68, 2015

17. Dudley RR, Aziz I, Bonnici A, Saluja RS, Lamoureux J, Kalmovitch B, et al: Early venous thromboembolic event prophylaxis in traumatic brain injury with low-molecular-weight heparin: risks and benefits. J Neurotrauma 27:2165-2172, 2010

18. Easterbrook PJ, Berlin JA, Gopalan R, Matthews DR: Publication bias in clinical research. Lancet 337:867-872, 1991

19. Epstein NE: Preoperative, intraoperative, and postoperative measures to further reduce spinal infections. Surg Neurol Int 2:17, 2011

20. Gonzalez AA, Shih T, Dimick JB, Ghaferi AA: Using samehospital readmission rates to estimate all-hospital readmission rates. J Am Coll Surg 219:656-663, 2014

21. Guzman JZ, Iatridis JC, Skovrlj B, Cutler HS, Hecht AC, Qureshi SA, et al: Outcomes and complications of diabetes mellitus on patients undergoing degenerative lumbar spine surgery. Spine (Phila Pa 1976) 39:1596-1604, 2014

22. Hamel MB, Henderson WG, Khuri SF, Daley J: Surgical outcomes for patients aged 80 and older: morbidity and mortality from major noncardiac surgery. J Am Geriatr Soc 53:424-429, 2005

23. Health Canada: Healthy Canadians-A Federal Report on Comparable Health Indicators 2012. Ottawa: Health Canada, 2013, pp 43-46

24. Jencks SF, Williams MV, Coleman EA: Rehospitalizations among patients in the Medicare fee-for-service program. $\mathbf{N}$ Engl J Med 360:1418-1428, 2009

25. Kassin MT, Owen RM, Perez SD, Leeds I, Cox JC, Schnier $\mathrm{K}$, et al: Risk factors for 30-day hospital readmission among general surgery patients. J Am Coll Surg 215:322-330, 2012

26. Kaye KS, Schmit K, Pieper C, Sloane R, Caughlan KF, Sexton DJ, et al: The effect of increasing age on the risk of surgical site infection. J Infect Dis 191:1056-1062, 2005

27. Kim BD, Smith TR, Lim S, Cybulski GR, Kim JYS: Predictors of unplanned readmission in patients undergoing lumbar decompression: multi-institutional analysis of 7016 patients. $\mathbf{J}$ Neurosurg Spine 20:606-616, 2014

28. Kim J, Gearhart MM, Zurick A, Zuccarello M, James L, Luchette FA: Preliminary report on the safety of heparin for deep venous thrombosis prophylaxis after severe head injury. J Trauma 53:38-43, 2002

29. Leppin AL, Gionfriddo MR, Kessler M, Brito JP, Mair FS, Gallacher K, et al: Preventing 30-day hospital readmissions: a systematic review and meta-analysis of randomized trials. JAMA Intern Med 174:1095-1107, 2014

30. Liberati A, Altman DG, Tetzlaff J, Mulrow C, Gøtzsche PC, Ioannidis JPA, et al: The PRISMA statement for reporting systematic reviews and meta-analyses of studies that evaluate healthcare interventions: explanation and elaboration. BMJ 339:b2700, 2009

31. Macdonald RL, Amidei C, Baron J, Weir B, Brown F, Erickson RK, et al: Randomized, pilot study of intermittent pneumatic compression devices plus dalteparin versus intermittent pneumatic compression devices plus heparin for prevention of venous thromboembolism in patients undergoing craniotomy. Surg Neurol 59:363-374, 2003

32. Marcus LP, McCutcheon BA, Noorbakhsh A, Parina RP, Gonda DD, Chen C, et al: Incidence and predictors of 30-day readmission for patients discharged home after craniotomy 
for malignant supratentorial tumors in California (19952010). J Neurosurg 120:1201-1211, 2014

33. Minshall CT, Eriksson EA, Leon SM, Doben AR, McKinzie BP, Fakhry SM: Safety and efficacy of heparin or enoxaparin prophylaxis in blunt trauma patients with a head abbreviated injury severity score $>2$. J Trauma 71:396-400, 2011

34. Moghavem N, Morrison D, Ratliff JK, Hernandez-Boussard T: Cranial neurosurgical 30-day readmissions by clinical indication. J Neurosurg 123:189-197, 2015

35. Nasir K, Lin Z, Bueno H, Normand SL, Drye EE, Keenan PS, et al: Is same-hospital readmission rate a good surrogate for all-hospital readmission rate? Med Care 48:477-481, 2010

36. Nuño M, Ly D, Ortega A, Sarmiento JM, Mukherjee D, Black KL, et al: Does 30-day readmission affect long-term outcome among glioblastoma patients? Neurosurgery 74:196-205, 2014

37. Oh T, Safaee M, Sun MZ, Garcia RM, McDermott MW, Parsa AT, et al: Surgical risk factors for post-operative pneumonia following meningioma resection. Clin Neurol Neurosurg 118:76-79, 2014

38. Rambachan A, Smith TR, Saha S, Eskandari MK, Bendok BR, Kim JY: Reasons for readmission after carotid endarterectomy. World Neurosurg 82:e771-e776, 2014

39. Rich MW, Vinson JM, Sperry JC, Shah AS, Spinner LR, Chung MK, et al: Prevention of readmission in elderly patients with congestive heart failure: results of a prospective, randomized pilot study. J Gen Intern Med 8:585-590, 1993

40. Rumball-Smith J, Hider P: The validity of readmission rate as a marker of the quality of hospital care, and a recommendation for its definition. N Z Med J 122:63-70, 2009

41. Ryan SL, Sen A, Staggers K, Luerssen TG, Jea A: A standardized protocol to reduce pediatric spine surgery infection: a quality improvement initiative. J Neurosurg Pediatr 14:259-265, 2014

42. Sarda S, Bookland M, Chu J, Shoja MM, Miller MP, Reisner $\mathrm{SB}$, et al: Return to system within 30 days of discharge following pediatric non-shunt surgery. J Neurosurg Pediatr 14:654-661, 2014

43. Shah MN, Stoev IT, Sanford DE, Gao F, Santiago P, Jaques DP, et al: Are readmission rates on a neurosurgical service indicators of quality of care? J Neurosurg 119:1043-1049, 2013

44. Smith JS, Saulle D, Chen CJ, Lenke LG, Polly DW Jr, Kasliwal MK, et al: Rates and causes of mortality associated with spine surgery based on 108,419 procedures: a review of the Scoliosis Research Society Morbidity and Mortality Database. Spine (Phila Pa 1976) 37:1975-1982, 2012

45. Suri MF, Qureshi AI: Readmission within 1 month of discharge among patients with acute ischemic stroke: results of the University HealthSystem Consortium Stroke Benchmarking study. J Vasc Interv Neurol 6:47-51, 2013

46. Takahashi S, Suzuki A, Toyoda H, Terai H, Dohzono S, Yamada K, et al: Characteristics of diabetes associated with poor improvements in clinical outcomes after lumbar spine surgery. Spine (Phila Pa 1976) 38:516-522, 2013

47. Vaziri S, Cox JB, Friedman WA: Readmissions in neurosurgery: a qualitative inquiry. World Neurosurg 82:376-379, 2014

48. von Elm E, Altman DG, Egger M, Pocock SJ, Gøtzsche PC, Vandenbroucke JP : The Strengthening the Reporting of Observational Studies in Epidemiology (STROBE) statement: guidelines for reporting observational studies. J Clin Epidemiol 61:344-349, 2008

49. Wang MC, Shivakoti M, Sparapani RA, Guo C, Laud PW, Nattinger AB: Thirty-day readmissions after elective spine surgery for degenerative conditions among US Medicare beneficiaries. Spine J 12:902-911, 2012

50. Wilson SJ, Kincade P, Saling MM, Bladin PF: Patient readmission and support utilization following anterior temporal lobectomy. Seizure 8:20-25, 1999

51. Wren SM, Martin M, Yoon JK, Bech F: Postoperative pneumonia-prevention program for the inpatient surgical ward. J Am Coll Surg 210:491-495, 2010

52. Wrubel DM, Riemenschneider KJ, Braender C, Miller BA, Hirsh DA, Reisner A, et al: Return to system within 30 days of pediatric neurosurgery. J Neurosurg Pediatr 13:216-221, 2014

\section{Disclosures}

The authors report no conflict of interest concerning the materials or methods used in this study or the findings specified in this paper.

\section{Author Contributions}

Conception and design: all authors. Acquisition of data: Pshonyak, Lee. Analysis and interpretation of data: all authors. Drafting the article: all authors. Critically revising the article: all authors. Reviewed submitted version of manuscript: all authors. Approved the final version of the manuscript on behalf of all authors: Cusimano. Administrative/technical/material support: all authors. Study supervision: Cusimano, Ilie.

\section{Correspondence}

Michael D. Cusimano, Division of Neurosurgery, St. Michael's Hospital, 30 Bond St., Toronto, ON M5B 1W8, Canada. email: injuryprevention@smh.ca. 